\title{
False negative electrical epidural stimulation test due to the excessive impedance of a saline bridge
}

\author{
Jordan D. Hill, MD (1) - Ban C. H. Tsui, MD, MSc, FRCPC
}

Received: 28 December 2020/Revised: 30 December 2020/Accepted: 30 December 2020/Published online: 25 January 2021

(c) Canadian Anesthesiologists' Society 2021

\section{To the Editor,}

The epidural stimulation test (EST) can predict successful neuraxial analgesia by confirming the location of the epidural catheter tip. ${ }^{1}$ Over the past 20 years, this technique's effectiveness has been confirmed in multiple studies; however, concerns about its reliability in clinical practice settings persist. ${ }^{2}$ In particular, its negative predictive value has been called into question as failed tests (inability to generate adequate current) and false negatives (no muscular twitches despite expected current) have been anecdotally reported and are often interpreted with ambiguity. Contrasting the reliability of the EST in clinical trials, we hypothesize that these failures may be due to important electrical current considerations easily overlooked by practitioners unfamiliar with the test. Recently, we encountered a series of false negative results. Upon reviewing the configuration of the EST assembly, we discovered that some clinicians had placed extension tubing between the electrode and the epidural catheter (Figure). Thus, we performed an in vitro study to validate whether the addition of this extension (i.e., a "saline bridge") could yield a failed EST.

We compared the impedance between a wire-reinforced epidural catheter (Perifix, B. Braun, Bethlehem, PA, USA) connected directly to the Arrow-Johans Electrocardiography (ECG) adapter (Teleflex, Morrisville, NC, USA) with the same epidural catheter with a salinefilled tubing extension (Statlock Epidural Stabilization Device, BD, Franklin Lakes, NJ, USA). We found that

J. D. Hill, MD - B. C. H. Tsui, MD, MSc, FRCPC ( $\varangle)$

Department of Anesthesiology, Perioperative, and Pain

Medicine, Stanford University School of Medicine, Palo Alto, CA, USA

e-mail: bantsui@stanford.edu even a short saline bridge added enough circuit impedance that the $95 \mathrm{~V}$ stimulator (Braun HNS 12, Bethlehem, PA, USA) could deliver no more than $1 \mathrm{~mA}$ regardless of the pulse-width applied. According to Ohm's law, ${ }^{3}$ this suggested that the added saline extension significantly increased the impedance of the circuit. With such high impedance, most commercially available nerve stimulators would not be able to generate sufficient amperage (2-15 $\mathrm{mA})^{4}$ to produce a positive motor response. Hence, we caution anesthesiologists against using extension tubing during an EST. We also noticed that any air within the system similarly made it impossible to deliver sufficient current, and that air bubbles tended to coalesce within the ECG adapter. Care is needed to ensure that the system is free of air bubbles before an EST is performed. While other variations of the system were tested (different techniques for connecting the anode to the ECG adapter, exchanging catheter clamps, and testing different lengths of epidural catheters), none of them had as significant an effect on the impedance of the system as the presence of a saline extension or air did.

Importantly, even properly placed epidural catheters with appropriate impedance can still yield false negatives if inadequate electrical charges (i.e., product of voltage, current, and time) are applied. Most nerve stimulators allow users to set the current while some also allow users to set the pulse-width (time). The maximum voltage can vary significantly between devices. It should be noted that a pulse-width of $0.1 \mathrm{msec}$ will provide significantly less charge than a pulse-width of $1.0 \mathrm{msec}$ at the same current and voltage. Accordingly, the range of current expected to produce a muscular twitch may need to be adjusted based on the pulse-width. Higher current will be needed to produce a twitch at a pulse-width of $0.1 \mathrm{msec}$ than at 1.0 msec. ${ }^{5}$ We also noted that nerve stimulators have different 


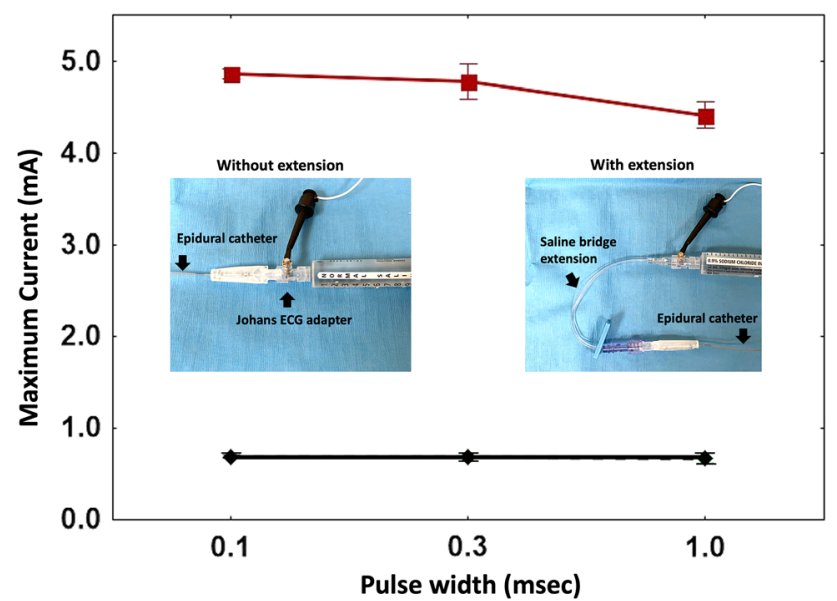

Figure The maximum amperage delivery with HNS 12 (Braun, Bethlehem, PA, USA) stimulator. The measurements were performed five times. The mean (with $95 \%$ confidence intervals) maximum amperage that the stimulator could generate with (black diamond) and without (red square) a saline bridge extension are plotted.

ways of alerting the clinician that the set current is not being delivered despite the application of maximum voltage (due to too much impedance). If this is missed, a failed test could easily be interpreted as a negative one. We recommend that clinicians familiarize themselves with their nerve stimulator and choose a device and settings that can produce adequate charges.
Disclosures None.

Funding statement None.

Editorial responsibility This submission was handled by Dr. Hilary P. Grocott, Former Editor-in-Chief, Canadian Journal of Anesthesia.

\section{References}

1. Tsui BC, Gupta S, Finucane B. Confirmation of epidural catheter placement using nerve stimulation. Can J Anaesth 1998; DOI: https://doi.org/10.1007/BF03012093.

2. Kwofie MK, Launcelott $G$, Tsui BC. Determination of thoracic epidural catheter placement: electrical epidural stimulation (Tsui test) is simple, effective, and under-utilized. Can J Anesth 2019; 66: $360-4$.

3. Tsui BC, Sze CK. An in vitro comparison of the electrical conducting properties of multiport versus single-port epidural catheters for the epidural stimulation test. Anesth Analg 2005; DOI: https://doi.org/10.1213/01.ANE.0000181006.36917.3E.

4. Tsui BC. Epidural stimulation test criteria. Anesth Analg 2006; DOI: https://doi.org/10.1213/01.ANE.0000227123.96546.69.

5. Tsui BC, Tsui JH, Corry GN. Estimation of equivalent threshold currents using different pulse widths for the epidural stimulation test in a porcine model. Can J Anesth 2014; DOI: https://doi.org/ 10.1007/s12630-013-0096-3.

Publisher's Note Springer Nature remains neutral with regard to jurisdictional claims in published maps and institutional affiliations. 